\title{
Penerapan Pembelajaran STEAM untuk Mengembangkan Kreativitas Siswa Sekolah Dasar di Daerah Terluar Terdepan Tertinggal Indonesia
}

\author{
Eva Luthfi Fakhru Ahsani \\ Institut Agama Islam Negeri Kudus \\ evaluthfi@iainkudus.ac.id \\ Yva Alfiana Nurhaliza \\ Institut Agama Islam Negeri Kudus \\ Ivalfiana92@gmail.com
}

\begin{abstract}
Abstrak
The purpose of this research is to apply STEAM learning to develop the creativity level of Elementary School Students in the Outermost Disadvantaged Regions of Indonesia. The application of loose parts in STEAM learning is considered capable of developing the creativity of elementary school children. This type of research inclades field research with qualitative descriptive methods. The stubjects of this study were the fourth graders of SD Inpres Oeteta, Sulamu District, Kupang Regency, East Nusa Tenggara. Methods of data collection using interview techiques, observation, and documentation. The result of this research is that STEAM learning can develop students' skills in the fields of Science, Technology, Engineering, Art and Mathematical using materials available in the environment. In addition, STEAM learning is able to make children have creativity in ways of thinking, solving problems and being able to think scientifically.
\end{abstract}

Keywords: STEAM Learning, Student Creativity, Indonesia's Outermost Disadvantaged Regions

\begin{abstract}
Abstrak
Tujuan penelitian ini adalah menerapkan pembelajaran STEAM untuk mengembangkan tingkat kreativitas Siswa Sekolah Dasar di Daerah Terluar Terdepan Tertinggal Indonesia. Penerapan loose parts pada pembelajaran STEAM dipandang mampu mengembangkan kreativitas anak sekolah dasar. Jenis penelitian ini termasuk penelitian lapangan (field research) dengan metode deskriptif kualitatif. Subjek penelitian ini adalah kelas IV SD Inpres Oeteta Kecamatan Sulamu Kabupaten Kupang, Nusa Tenggara Timur. Metode pengumpulan data menggunakan teknik wawancara, observasi, dan dokumentasi. Hasil penelitian ini yaiti Pembelajaran STEAM dapat mengembangkan keterampilan siswa dalam bidang Science, Technology, Engineering, Art and Mathematic dengan menggunakan bahan yang tersedia di lingkungan sekitar. Selain itu juga pembelajaran STEAM mampu menjadikan anak
\end{abstract}


nemiliki kreativitas dalam cara berfikir, memecahkan masalah dan mantpu berfikir ilmiah.

Kata kunci: Pembelajaran STEAM, Kreativitas Siswa, Daerah Terluar Terdepan Teringgal Indonesia

\section{A. Pendahuluan}

Pendidikan menjadi peran penting dalam kehidupan manusia. Fungsi Pendidikan memegang peran penting dalam pembangunan banga dan negara indonesia. Upaya menuju bangsa indonesia yang mandiri, kreatif dan inovatis tidak dapat terlepas dari pendidikan nasional. Dalam rangka pembangunan pendidikan nasional telah ditetapkan beberapa undangundang yang terkait dengan pendidikan, diantaranya adalah UU nomer 9 tahun 2009 tentang badan hukum pendidikan. Berbagai undang-undang akan menjadi payung hukum dalam penyelenggaraan pendidikan di indonesia agar mampu meningkatkan kualitas SDM dan membuka akses seluas-luasnya kepada masyarakat untuk mendapatkan pelayanan pendidikan yang berkualitas.

Meskipun Indonesia notabene sebagai negara yang sangat kaya dengan sumber daya alam yang melimpah. Tetapi dalam dunia pendidikan indonesia masih dihadapkan dengan beberapa masalah yang perlu diperbaiki. Terutama Pendidikan di daerah $3 \mathrm{~T}$ (Terdepan, Terluar, Tertinggal) yang terkenal dengan permasalahan yang kompleks. Diantaranya yaitu terkait dengan guru atau SDM yang masih kurang. Hal tersebut terlihat dalam profil sekolah dasar Inpres Oeteta sulanu kupang Nusa tenggara timur. Dimana dalam sekolah tersebut tidak adanya guru ataı SDM yang mengampu mata pelajaran agama islam, tidak tersedianya perpustakaan. Selain itu menurut penelitian dari Anang Kabul Prastyo dan Novi Krniasih (2017) menyatakan bahwa kesulitan guru ataupun SM-3T dalam menampaikan materi pelajaran karena minimnya media pembelajaran di sekolah-sekolah daerah 3T. permasalahan lain yaitu masih tingginya angka putus sekolah, sementara angka partisipasi atau kesadaran akan pentingnya pendidikan itu masih rendah.

Kementrian pembangunan daerah tertinggal (PDT) mengungkapkan bahwa daerah $3 \mathrm{~T}$ adalah daerah yang termasuk dalam kategori tertinggal dari akses, terpencil dari letak geografis, lamban dari segi pertumbuhan dan terluar dari jangkauan pusat layanan pendidikan (Murniasih, 2013). Dari berbagai penelitian di beberapa daerah 3 T daerah perbatasan Kayan Hulu Malinau (A'ing, 2015) dan Bintan Pesisir Kepulauan Riau (Auldina, 2018), kepulauan Nasi Aceh besar (Adlim, Gusti, \& Zulfadi, 2016) mendapatkan hasil penelitian yang mengungkapkan kondisi dan pengembangan pendidikan di daerah tersebut daerah $3 \mathrm{~T}$ masih sangat terbatas, bahkan cenderung didiskriminasi dan dimarjinalkan (Imam, 2020).

Dewasa ini abad 21 menjadi tantangan pendidikan di indonesia untuk menyiapkan upaya-upaya yang harus dilakukan sesuai dengan perkembangan ilmu pengetahuan dan teknologi serta bersaing secara global. Diantaranya yaitu upaya untuk meningkatkan keterampilan berpikir kritis, pemecahan masalah, komunikasi, kolaborasi dan kreativitas. 
Berdasarkan perkembangan ilmu dan teknologi yang begitu cepat, kreativitas memegang peranan yang sangat penting untuk disiapkan agar siswa siap menghadapi hal tersebut. Berdasarkan peraturan yang ditetapkan oleh permendikbud tentang kompetensi inti dan kompetensi dasar jenjang sekolah dasar no 37 pasal 2A tahun 2018 atau pada muatan lokal. bahwa muatan informatika pada SD/MI digunakan sebagai alat pembelajaran dan dapat dipelajari melalui ekstrakulikuler. Dalam hal ini guru dituntut untuk terampil dalam menggunakan teknologi atau alat dalam proses pembelajaran. Hal ini senada dengan teori Bloom yang mengemukakan bahwa kreativitas merupakan kemampuan yang paling tinggi dalam aspek perkembangan kognitif, oleh karena itu kreativitas sangat penting diberikan pada pendidikan anak usia sekolah dasar.

Istilah lain dari teknologi adalah alat. Teknologi bukan hanya berupa barang elektronik atau digital seperti komputer, mesin-mesin canggih ataupun kamera. Pensil, krayon, penggaris dan gunting juga merupakan alat. Teknologi adalah Peralatan apapun yang digunakan anak untuk bermain. Mulai dari teknologi yang sederhana ang mudah anak-anak temui dalam kehidupan sehari-hari sampai dengan modern. Hal yang perlu dipastikan mengenai teknologi untuk anak yaitu dalam hal kegunaan yang sesuai kemauan anak serta dalam pemberian kesempatan untuk memecahkan masalah. Penugasan berbasis teknologi dapat membina kebiasaan siswa untuk mencari dan mengelola sendiri informasi dan komunikasi (Isnaeni \& Ahsani, 2021).

Pemberian stimulasi kreativitas pada pembelajaran pada anak usia sekolah dasar bisa dilakukan melalui strategi yang bermacam-macam. Yang dilakukan untuk menghadapi abad 21 atau revolusi industri 4.0 adalah pembelajaran dengan metode STEAM (science, technology, engginering, art, and mathematics) yang melibatkan siswa pada pada subyek STEAM yang memiliki tujuan memicu minat dan kecintaan pada ilmu dan seni pada anak-anak sejak usia dini. Metode STEAM juga melibatkan proses kreatif, pembelajaran yang relevan dalam mempersiapkan siswa untuk siap menjadi inovator yang terus berkembang. Sains seringkali menjadi mata pelajaran yang membuat anak-anak penasaran, bersemangat, dan haus akan belajar. Pembelajaran berbasis STEAM memiliki unsur yang penting yaitu loose parts. Loose parts (lepasan) merupakan barang-barang yang mudah ditemukan di lingkungan sekitar. Seperti ranting, daun, bunga, dan benda-benda alam lainnya. Yang memang sesuai dengan potret daerah $3 \mathrm{~T}$ yang kaya akan sumber daya alamya.

Tujuan penelitian ini adalah mengetahui penerapan metode STEAM (science, technology, engginering art, and mathematics) terhadap pembelajaran pada anak sekolah dasar di daerah $3 \mathrm{~T}$ (Terdepan, Terluar, TertinggaI) untuk mengembangankan kreatifitas anak melalui model pembelajaran yang aktif dan kreatif atau student canter dalam menggali informasi dan memecahkan masalah berkaitan dengan hal-hal baru dalam diri anak tersebut sesuai dengan lingkungan sekitarnya. 
Jenis penelitian ini termasuk penelitian lapangan (ficld research) dengan metode deskriptif kualitatif. Subjek penelitian ini adalah kelas IV dengan jumlah 24 siswa SD Inpres Oeteta Kecamatan Sulamu Kabupaten Kupang, Nusa Tenggara Timur. Penelitian ini bertujuan untuk mengembangkan tingkat kreativitas anak sekolah dasar di daerah $3 \mathrm{~T}$ dengan penerapan pembelajaran STEAM. Metode pengumpulan data menggunakan teknik wawancara, observasi, dan dokumentasi. Teknik analisis data penelitian menggunakan versi analisis data Miles dan Huberman, bahwa ada tiga alur kegiatan, yaitu reduksi data, penyajian data, serta penarikan kesimpulan atau verifikasi (Usman \& Akbar, 2009)

\section{B. Pembahasan}

\section{Potret Pendidikan Sekolah Dasar di Daerah $3 T$}

Daerah 3 T (Terdepan, Terluar dan Tertinggal) merupakan daerah yang dikategorikan tertinggal dari segi akses, terpencil dari segi letak geografis, lamban dari segi pertumbuhan, dan terluar dalam jangkauan dari pusat layanan pendidikan (Rencana Pembangunan Jangka Menengah, 2015). Seperti di daerah indonesia bagian timur tepatnya di SD Inpres Oeteta kecamatan sulamu kabupaten Kupang yang mengalami kurangnya tenaga pendidik dan kependidikan, minimnya sarana dan prasana pendidikan untuk menunjang sebuah pembelajaran. SD Inpres Oeteta merupakan sekolah Negeri yang mana sekolah ini berdiri pada 17 juli tahun 1983, yang mana kondisi awal dari sekolah ini masih berupa hutan belantara dan pada saat itu tingkat pendidikan masih rendah. Profil guru SD Inpres, yaitu memiliki guru sebanyak 13 orang, dimana 7 orang berstatus sebagai PNS dan 5 Orang berstatus sebagai honorer dan 1 orang guru kontrak.

Hasil observasi dan wawancara guru kelas IV garda terdepan Kab. Manggarai Timur bahwa sebagian besar sekolah adalah sekolah baru, beberapa diantaranya belum memiliki gedung sekolah, Laboratorium dan perpustakaan yang ada masih terbatas atau tidak ada, Guruguru pengampu merupakan alumni dari universitas atau LPTK lokaI di daerah 3T (Terdepan, Terluar dan Tertinggal), pengalaman paedagogik dan profesional guru masih jauh dari standar nasional pendidikan, pembelajaran masih teacher center, dan kemampuan pemahaman sains, teknologi dan lingkungan masih rendah.

SD inpres belum tersedia sarana dan prasarana yang sesuai dengan kebutuhan untuk mencapai tujuan pembelajara sesuai apa yang diinginkan. Sedangkan dalam pembelajaran, perlu adanya pendidik yang berkompeten untuk menyiapkan upaya-upaya dalam meningkatkan keterampilan berpikir kritis, pemecahan masalah, komunikasi, kolaborasi dan kreativitas. Berdasarkan perkembangan ilmu dan teknologi yang begitu cepat, kreativitas memegang peranan yang sangat penting untuk disiapkan agar siswa siap menghadapi hal tersebut. Guru wajib mengikuti kemajuan zaman yang semakin berkembang serta mampu menggunakan teknologi untuk meningkatkan kompetensi (Shofia \& Ahsani, 2021). 
Perkembangan sains dan teknologi membawa manfaat dalam pembelajaran (Ahsani et al., 2020).

\section{Pembelajaran STEAM di SD Inpres Oeteta Daerah $3 T$}

Pembelajaran STEAM adalah pola pembelajaran yang menggabungkan antara science, technology, engineering, art, dan mathematic. Pembelajaran STEAM dapat memicu kreativitas dengan meningkatkan pemikiran siswa yang lebih mandiri, fleksibel, kreatif dan memiliki keterampilan cara berfikir ilmiah dalam memecahkan masalah (Zubaidah, 2019). kreativitas dapat dipelajari melalui contoh dan praktik, oleh karena itu guru diharapkan dapat mengintegrasikan model-model pembelajaran, sehingga menjadikan kegiatan pembelajaran yang menyenangkan dan efektif. Guru yang profesional dituntut adanya kompetensi untuk menyampaikan kreativitas serta mampu melakukan improvisasi, sehingga proses pembelajaran tidak membosankan (Marni, 2020). Melalui aktivitas pembelajaran dengan pendekatan STEAM, diharapkan siswa mampu meningkatkan kualitas belajar. Kegiatan-kegiatan untuk mengembangkan kreativitas dapat dimplementasikan sejak sekolah dasar dengan media pembelajaran yang sederhana dan mudah didapatkan disekitar.

Penyesuaian daerah 3T yang kaya akan sumber daya alam dengan S dalam STEAM merupakan salah satu contoh penerapan dari unsur penting dari STEAM yaitu loose parts. (Buhrin, 2019) Loose Parts adalah bahan yang dapat dipindahkan, dibawa, digabungkan, didaur ulang dengan berbagai cara. Loose parts dapat membantu untuk mengembangkan atau menciptakan kreativitas dalam proses pembelajaran anak. Pembelajaran ini dapat menjadi strategi untuk anak dalam mengembangkan berbagai keterampilan dengan menggunakan bahan yang tersedia di lingkungan sekitar.

Berdasarkan penggunaan loose parts dalam pembelajaran STEAM dapat menjadikan orang tua dan guru mampu memanfaatkan dan mendapatkan loose parts dari manapun tanpa mengeluarkan biaya. Dengan membantu anak menghubungkan dirinya dengan alam, loose parts juga dapat digunakan pengembangkan imajinasi, kreativitas bahasa dan pengetahuan anak. Loose parts bukan hanya mendukung perkembangan anak, tetapi dapat juga membantu anak untuk menghubungkan dirinya menyesuaikan dengan lingkungannya. Metode STEAM dan Loose Parts ini penting untuk melatih anak berfikir secara kritis serta membangun cara berfikir logis dan sistematis. Melalui metode ini anak akan senang jika diajak bermain. Dengan menggunakan metode STEAM dan Loose Parts dalam pembelajaran, anak akan mudah untuk meningkatkan daya kreativitasnya (Syafi'i \& Dianah, 2016).

Pembelajaran ini dapat menjadikan strategi untuk guru dalam mengembangkan berbagai keterampilan kreativitas anak dengan menggunakan bahan atau media pembelajaran yang ada di sekitar lingkungan. Bermain di lingkungan luar dengan loose parts dalam pembelajaran STEAM dapat mengembangkan anak-anak untuk memiliki tingkat keterlibatan dan pengaruh prositif pada perilakı dan perkembangan mereka (Alfira, 2019). 
Selain itu penerapan pembelajaran STEAM dapat mendorong anak dalam hal mengembangkan rasa keingin tahuannya, berani dalam mengajukan pertanyaan sehingga dapat membangun pengetahuan melalui mengeksplorasi, mengamati, menemukan dan memecahkan masalah yang ada di sekitar. Dengan lingkungan yang mendukung anak mampu membuat koneksi antara bahan pembelajaran, lingkungan sekitar, dan desain pembelajaran ( $S i t i, 2020$ ).

\section{Pembelajaran STEAM dapat Mengembangkan Kreativitas}

Pembelajaran Sekolah Dasar di daerah 3T membutuhkan adanya penguatan mengenai pendidikan karakter dalam pembelajaran yang efektif (Rifada, 2019) (Nafisah \& Zafi, 2020). Menumbuh kembangkan minat belajar anak-anak di daerah $3 \mathrm{~T}$ perlu adanya pendekatan khusus serta motivasi-motivasi yang dapat menghasilkan berubahan. Beberapa keterampilan atau kreativitas tersebut perlu dimiliki oleh siswa untuk menghadapi tantangan abad 21 ini, hendaknya relevan sesuai dengan tantangan dan tuntutan pada kehidupan nyata sehari-hari. Diantaranya yaitu kemampuan dalam memecahkan masalah, kemampuan bekerjasama, kemampuan untuk berfikir kritis, analitis, kreatif dan inovatif, kemampuan menguasai teknologi dan kemampuan mengolah informasi serta komunikasi. Hal tersebut dapat dilatih dengan pembelajaran STEAM yang mempunyai keselarasan dengan kurikulum 2013 yakni peserta didik dituntut tidak hanya unggul dalam kognitifnya saja tetapi afektif dan psikomotoriknya juga.

Dampak penerapan pembelajarn STEAM dalam pembelejaran anak usia dasar salah satunya yaitu berupa pengembangan kreativitas siswa, atau sebagai sarana untuk meningkatkan keterampilan pemecahan masalah dalam kegiatan sehari-hari. Alasan yang menjelaskan model STEAM dapat meningkatkan kreativitas anak adalah Pembelajaran berbasis STEAM dapat melatih siswa dalam menerapkan pengetahuan sebagai bentuk pemecahan masalah berdasarkan lingkungan dengan memanfaatkan teknologi. Penerapan STEAM dalam pembelajaran dapat mendorong siswa untuk mendesain, manipulatif dan afektif serta mengaplikasikan pengetahuan (Kapila \& Iskander, 2014). Pembelajaran STEAM mengajak anak usia sekolah dasar untuk menciptakan hal-hal berdasarkan daya pikir sesuai imajinasi sendiri sehingga memungkinkan bagi anak tersebut untuk membentuk pola pikir yang baik dan kreatif.

Pengenalan STEAM untuk anak usia sekolah dasar dapat dilakukan dengan menciptakan lingkungan belajar yang aman dan menyenangkan. Dimana lingkungan tersebut dapat memberikan kesempatan pada anak untuk bereksplorasi, menemukan, membangun, melakukan percobaan, bekerjasama memecahkan masalah dengan mengaitkan kehidupan nyata sehari-hari. Pendekatan STEAM adalah isu tentang cara atau strategi pembelajaran yang dirokemendasikan pada ahli untuk diterapkan pada setiap jenjang pendidikan mulai dari usia dini sampai pendidikan tinggi. Hal tersebut dikarenakan STEAM mampu mengembangkan 
berbagai keterampilan, kerja kelompok, analisis kritis, berpikir independent, inisiatif, komunikasi dan literasi digital (Suci, 2019).

Pembelajaran STEAM hadir sebagai jawaban untuk kebutuhan dalam meningkatkan minat dan keterampilan siswa dalam bidang Science, Technology, Engineering, Art and Mathematic. STEAM adalah pendekatan pembelajaran yang memberi peluang siswa untuk memperluas pengetahuan dalam sains dan humaniora dan untuk mengembangkan keterampilan komunikasi, kemampuan berfikir kritis, berkelompok, kreativitas, dan keterampilan lainnya. Atrs atau seni merupakan bentuk pengekspresian atau mewakili ide-ide siswa selain membaca, menulis, berbicara dan mendengarkan.

Dalam hal ini STEAM memberdayakan guru untuk dapat mengaplikasikan pembelajaran pembelajaran berbasis proyek yang melibatkan lima disiplin ilmu. Loose parts (lepasan) merupakan barang-barang yang mudah ditemukan di lingkungan sekitar. Seperti ranting, daun, bunga, dan benda-benda alam lainnya. Yang memang sesuai dengan potret daerah $3 \mathrm{~T}$ yang kaya akan sumber daya alamya. Orang tua dan guru mampu memanfaatkan dan mendapatkan loose parts dari manapun tanpa mengeluarkan biaya. Dengan membantu anak menghubungkan dirinya dengan alam, loose parts juga dapat digunakan pengembangkan imajinasi, kreativitas bahasa dan pengetahuan anak.

\section{Kesimpulan}

Dearah 3T (Terndepan, Terluar, dan Tertinggal) adalah daerah jika ditinjau dari segi pendidikan masih memiliki tingkat pendidikan yang rendah, pengalaman paedagogik dan profesional guru masih jauh dari standar nasional pendidikan, pembelajaran masih teacher center, sarana prasarana yang kurang memadahi dan kemampuan dasar membaca dan matematik masih rendah. Pembelajaran STEAM hadir sebagai jawaban untuk kebutuhan dalam meningkatkan minat dan keterampilan siswa dalam bidang Science, Technology, Engineering, Art and Mathematic. Untuk menumbuhkembangkan kreativitas perlu literasiliterasi sebagai sumber informasi dalam pembelajaran STEAM. Loose parts dapat membantu untuk mengembangkan atau menciptakan kreativitas dalam proses pembelajaran anak. Pembelajaran ini dapat menjadi strategi untuk anak dalam mengembangkan berbagai keterampilan dengan menggunakan bahan yang tersedia di lingkungan sekitar. Selain itu juga pembelajaran STEAM mampu menjadikan anak nemiliki kreativitas dalam cara berfikir, memecahkan masalah dan mampu berfikir ilmiah. 


\section{DAFTAR PUSTAKA}

Ahsani, E. L. F., Rusilowati, A, \& Anni, C. T. (2020). The Development of Integrated Science Teaching Materials Based on the Science Literacy of Fifth Graders. 1st ICONECT International Conference Education, Culture and Technology, Query date: 2020-08-14 $14: 24: 03,65-71$.

Dimyanti, Musa. (2020). Melihat Peluang Dan Tantangan Pembelajaran IPA Di Daerah $3 T$ Sebagai Bekal Calon Guru Yang Profesional. Prosiding Kuliah Tamu Online Mahasiswa PGMI. Institut Agama Islam Negeri Kudus

Hambali, Imam Fitri. (2020). Pendidikan Di Daerah Kepulauan Terpencil : Potret Siswa, Guru, Dan Sumber Belajar. Jurnal Pendidikan Edutama, 7 (1), 76

Hanifah, Rifda Isna. (2019 September 9) Penerapan Digital Leaming Dalam Pengetahuan Maslah Pendidikan Di Indonesia Di Daerah $3 T$ (Terdepan, Trpencil, dan Tertinggal). Dari https://wwt.kompasiana.com/rifdaisna/5dbe5792097/362aa2365834/penerapandigital-Laming-dalam-pengentasan-masalah-pendidikan-di-indonesia-di-dacrah-3iterdepan-terpencil-dan-tertinggal?page $=$ all

Harsono, Fitri haryanti. (2019, Januari 1) Berita Liputan 6 https://ww.liputan6.com/health/read/3877867/solusi-wujudkan-pendidikan-yangefektif-di-wilayah-3i. Diakses 31 mei 2020

Husaini Usman dan Pumomo Setiadi Akbar, Metodologi Penelitian Sosial, (Jakarta: PT Bumi Aksara, 2009), hlm. 85-89.

Isnaeni, A., \& Ahsani, E. L. F. (2021). Strategi Pembelajaran Daring Dengan Model Resitasi Berbasis Teknologi Bagi Siswa MI/SD. As-Sibyan, 3(2), 12-20. https://doi.org/10.52484/as_sibyan.v3i2.196

Joenady, A. M. (2019). Konsep dan Strategi Pembelajaran di Era Revolusi 4.0. Yogyakarta: Laksana

Kabul P. Anang, Novi Kumiasih. (2017, Oktober 10). KOMIKTOR (Komputer Mini Plus Proyektor) Bertenaga Surya Sebagau Solusi Meningkatkan Kualitas Media Pembelajaran Untuk Daerah 3T Guna Menyongsong Pemerataan Media Pembelajaran Di Indonesia tahun 2025. Teknologi Pendidikan Universitas Negeri Semarang. https://www researchgate.net/publication/331476644

Limbong Irmayani, Muniroh M. \& Nila K. (2019, Desember 12). Perencanaan Pembelajaran Paud Berbasis STEAM. Dari http://conference.upgris.acid/indexphp/Snpaud2019/artide/view/450

Marni. (2020). Upaya Meningkatkan Aktivitas dan Hasil Belajar Siswa Melalui Model Pembelajaran Course Riview Horay SDN Sumbermulyo 02 Pati. Al Hikmah: Journal of Education, 1(2), 109-124.http://yphn.ac.id/ejournal/index.php/Alhikmah/index

Munawar. M, Fenny, Sugiyanti. (2019). Implemention of stame - based early childhood education learning in semarang city. Jurnal Ceria, (2). 4 
Murniasih, Subagia, Nyoman, 2013, Pengelolaan Pembelajaran Ipa: Studi Kasus Pada Smp Si Daerah Terdepan, Terluar Dan Tertinggal, E-Program Pascasarjana Pendidikan Ganesha Program Studi Administrasi, 4. https://www.neliticom/id/publications/76241/potret-pengelolaan-pembelajaran-ipastudi-kasus-di-daerah-terdepan-terluar-dan-t. Diakses 28 Mei 2020

Nafisah, F. T., \& Zafi, A. A. (2020). Model Pendidikan Karakter Berbasis Keluarga Perspektif Islam di Tengah Pendemi Covid-19. Ta'allum: Jumal Pendidikan Islam, 8(1), 1-20. https://doi.org/10.21274/taalum.2020.8.1.1-20

Putri, Suci U. (2019). Pembelajaran Sains Untuk Anak Usia Dini. Bandung: Royyan Press

Shofia, N. A., \& Ahsani, E. L. F. (2021). Pengaruh Penguasaan It Guru Terhadap Kualitas Pembelajaran Dimasa Pandemi. FORUM PAEDAGOGIK, 12(2), 201-215. https://doi.org/https://doi.org/10.24952/paedagogik.v12i2.3901

Simarmata Janner, dkk. (2020). Pembelajaran STEM Berbasis Hots Dan Penerapanya: Yayasan Kita Menulis

Syafíi, I., \& Dianah, N. D. (2016). Pemanfaatan Loose Parts Dalam Pembelajaran Steam Pada Anak Usia Dini. AULADA: Jamal Pendidikan Dan Perkembangan Anak, III(1), 105114.

Zubaidah Siti. (2019, september 9). STEAM (Science, Technology, Engineering, Arts, And Mathenatics): Pembelajaran Untuk Memberdayakan Keterampilan Abad Ke-21. Pendidikan Biologi-FMIPA-Universitas Negeri Malang. hitps://www researchgatenet/publication/336065211 
Eva Luthfi Fakhru Ahsani \& Yva Alfiana Nurhaliza 